between the healthcare provider and the woman', 'enabling autonomy' and 'avoiding a paternalistic relationship'. Greater information for OVD in antenatal classes was suggested in order to counteract a common theme of negative perceptions of an operative delivery.

Conclusion Vulnerability of the women's feelings highlights the importance of non technical skills in ensuring a woman feels trust, is empowered and in control. These non-technical skills need to be taught, learnt and practised to ensure a woman's experience if safe, positive and pays justice to the delight of having a child.

\section{PL.34 A TWO YEARS AUDIT OF INCIDENCE, RISK FACTOR, MATERNAL AND NEONATAL OUTCOME OF UMBILICAL CORD PROLAPSE AT AL CORNICHE HOSPITAL ABU DHABI UAE}

doi:10.1136/archdischild-2013-303966.217

\section{T Perveen. Corniche Hospital, Abu Dhabi, United Arab Emirates}

To determine the incidence, risk factors, obstetric management, maternal and neonatal outcome of umbilical cord prolapse (UCP) in order to improve the obstetric services

Methodology This is retrospective audit of all the cases of Umbilical cord prolapsed at Corniche Hospital during January 2009 and December 2010.

Results Twenty three cases diagnosed as umblical cord prolapse The hospital based incidence of cord prolapse was 1:760. The mean Dignoses-Delivery Interval (DDI) was 18.5 Minutes. Eleven mothers $(47.8 \%)$ delivered within this period of time. Eighty two percent women were multiparous. $86.9 \%$ were singleton pregnancies while $13.1 \%$ were (three sets) of twin gestations. Fifteen pregnancies $(65.2 \%)$ were of more than 37 weeks of gestations. In $26.15 \%(n=6)$ cases, fetuses were presented as breech. In majority of the case $(n=17)$ general anaesthesia was given (74\%) for emrgency caesarean section (LSCS) and in 4 cases (17\%) spinal anaesthesia was chosen for caesarean delivery. Tewnty two (95.65\%) women were delivered by LSCS and one women had successful vaginal delivery after UCP.

Twenty three babies (80.7\%) had apgar score at 5 minutes $>7$. Umblical cord PH was done in $65.2 \%(n=15)$ of the cases. Arterial cord $\mathrm{PH}$ was recorded as less than 7.2 in $53.3 \%(\mathrm{n}=8)$ of the neonates. Sixteen babies required admission to NICU. We had 5 early neonatal deaths $(19.2 \%)$ in our case series. However, there was no case of stillbirth or HIE directly related to cord prolapse.

Conclusion Cord prolapse is a rare but true obstetric emergency associated with high perinatal morbidity and mortality but with quick diagnosis and prompt multidisciplinary team management the outcome can be improved.

\section{PL.35 OUTCOMES FOLLOWING INDUCTION OF LABOUR(IOL) IN THE EAST OF SCOTLAND}

doi:10.1136/archdischild-2013-303966.218

M Fawzy, V Balakumar, AE Nicoll. Ninewells Hospital and Medical School, Dundee, UK

Objectives To review delivery outcomes for IOL at Term in Ninewells Hospital Dundee and to determine whether maternal factors, indications and gestational age influence outcomes.

Methods Data were collected from all IOL at Term between 01/01/11-31/08/12. Information on outcomes was collected from the local maternity database (Torex Protos Evolution).

Results 1802/7499 (24\%) had IOL. Median age was 29 years (Range $=15-48$ years) and median BMI was $25.7 \mathrm{~kg} / \mathrm{m}^{2}$ (Range $\left.=15-66 \mathrm{~kg} / \mathrm{m}^{2}\right) .1020 / 1802(56.6 \%)$ were primiparous. Median gestational age was 40 weeks (Range 37-43 weeks).
$664 / 1802(36.8 \%)$ of IOL were for post-dates pregnancy, 280/1802 $(15.5 \%)$ were for prolonged pre-labour rupture of membranes (PROM), 194/1802 (10.7\%) were for hypertensive disease, 132/1802 $(7.3 \%)$ were for suspected fetal growth restriction (FGR) and 106/1802 (5.8\%) were for diabetes.1057/1802 (58.6\%) had spontaneous vertex delivery, 360/1802 (19.9\%) had operative vaginal; delivery (OVD) and 385/1802 (21.3\%) had caesarean section (CS). BMI > $30 \mathrm{~kg} / \mathrm{m}^{2}$ was associated with increased risk of CS $(R R=1.23 .95 \% C I=1.01-1.50, p=0.03)$, and this was independent of gestational age and indication. Women who had IOL for post dates pregnancy had higher rates of CS $(\mathrm{RR}=1.25 .95 \% \mathrm{CI}=1.05$ $1.50, \mathrm{p}=0.01)$ and $\mathrm{OVD}(\mathrm{RR}=1.28 .95 \% \mathrm{CI}=1.06-1.54, \mathrm{p}=0.01)$. Women who had IOL for suspected SGA fetus had lower rates of CS $(\mathrm{RR}=0.51,95 \% \mathrm{CI}=0.31-0.83, \mathrm{p}=0.003)$ Women who had IOL for PROM had lower rates of OVD $(\mathrm{RR}=0.57,95 \% \mathrm{CI}=0.43-0.76$, $\mathrm{p}<0001)$.

Conclusion The majority of women who have IOL at Term will have a vaginal delivery. Nevertheless the risk of operative intervention increases significantly in women who have IOL at 41 weeks gestation and beyond. due to IOL for post dates pregnancy. This data will be useful in counselling women requiring IOL at Term.

\section{PL.36 CATEGORY 1 CAESAREAN SECTIONS AND DECISION TO DELIVERY INTERVAL: ARE WE MISSING TARGET?}

doi:10.1136/archdischild-2013-303966.219

S Mustafa, M Wickramasingham, M Abdullah, OA Jibodu. York Teaching Hospitals NHS Foundation Trust, York, UK

Background NICE guidelines recommend decision-to-delivery interval (DDI) of 30 minutes for all category 1 Caesarean Sections (Cat1 CS).

Methods A retrospective analysis of 50 Cat1 CS carried out in a busy district hospital.

Results $44 \%$ of all Cat1 CS were done for suspected fetal compromise on CTG, followed by $30 \%$ for persistent fetal bradycardia $>6$ minutes. $64 \%$ deliveries happened during night shift and 34\% were undertaken by junior registrars. Decision to perform Cat1 CS was directly taken by consultant in $36 \%$ of cases with consultant being first surgeon in $78 \%$ of these cases mostly as resident on-call during nights. Mean decision-to-delivery interval was 18.8 minutes with $87 \%$ deliveries performed within targeted 30 minutes. $42 \%$ of Cat1 CS were performed under general anaesthetic with shortest mean DDI of 14.3 minutes compared to spinal anaesthesia (25 minutes) and epidural top-up (16.7 minutes). 16\% had massive PPH > 1.5 litres however average hospital stay was 3 days. $26 \%$ babies were admitted to SCBU with $61 \%$ being severely acidotic with cord $\mathrm{pH}<7.0$ or base excess $>12$. Mean DDI in these babies was 24 minutes.

Conclusion Targeted DDI of 30 minutes is difficult to achieve in $100 \%$ of cases. Use of General anaesthesia shortens the DDI interval but has its own implications. Resident on-call consultant night shifts increase direct consultant input and may influence outcomes. A significant number of babies required admission to SCBU with proportion of acidotic babies remaining high. Further measures are required to improve Decision-to-Delivery interval to improve perinatal outcomes.

\section{PL.37}

\section{MATERNAL ADIPOSITY AND CAESAREAN SECTION}

doi:10.1136/archdischild-2013-303966.220

V O'Dwyer, E Kent, Hogan JLK, C O'Connor, N Farah, MJ Turner. UCD Centre for Human Reproduction, Dublin, Ireland

Maternal obesity and rising caesarean section (CS) rates are important obstetric issues. High visceral fat (VF) is associated with an increased risk of medical conditions outside pregnancy and gestational diabetes mellitus. The purpose of the study was to assess risk 